\title{
GRANDO, Beleni Saléte (Org.). Jogos e culturas indígenas: possibilidades para a educação intercultural na escola. Cuiabá: EdUFMT, 2010. 171 p.
}

\author{
Keros Gustavo Mileski* \\ Paulo Caldas Ribeiro Ramon**
}

Jogos e culturas indígenas: possibilidades para a educação intercultural na escola é uma publicação organizada por Beleni Saléte Grando composta de sete capítulos, escritos por pesquisadores de diversas etnias e culturas. A partir de projetos e pesquisas desenvolvidos com financiamento ou em parceria com órgãos governamentais e diferentes instituições, os autores se esforçaram por sistematizar e discutir os resultados apresentados no livro que tem como tema central, ao longo de todas as discussões, os jogos indígenas e a educação intercultural, suas relações com o movimento e o corpo, bem como possibilidades pedagógicas baseadas em tais elementos.

O primeiro texto, intitulado Jogo de tabuleiro como prática educativa intercultural, escrito por Marina Vinha, "traz reflexões pontuando pesquisas realizadas com os indígenas Kadiwéu, habitantes no Mato Grosso do Sul” (VINHA, 2010, p. 23), tendo como objetivo "[...] refletir sobre o percurso sócio-histórico do jogo de tabuleiro" (VINHA, 2010, p. 23). A autora mostra a presença dessa prática entre indígenas no Brasil, ressaltando que nos primórdios nela estava presente um elemento de simulação, reconhecido como artifício tático de guerra. Sobre outro aspecto, apoiada em Gallahue e Ozmun (2005), considera também o elemento da psicomotricidade. Cabe aqui ressaltar que esses autores, cuja importância é reconhecida na Educação Física, categorizaram diferentes fases do desenvolvimento motor. Apoiados nos trabalhos de Jean Piaget, Erik Erikson e Urie Bronfenbrenner, fundamentam todo um campo da Educação Física, com perspectiva teórico-metodológica bem-definida.

Dessa forma, a posição de jogo é analisada relacionando-se com comportamentos e emoções específicos dos sujeitos envolvidos. Os movimentos e ações no jogo de tabuleiro se alteram de acordo com a idade e o contexto cultural. Considerando as transformações sociais, a autora destaca que os jogos de tabuleiro vão sendo ressignificados e passando por alterações constantes, em decorrência das dinâmicas sociais. Em um dos destaques dos relados descreve

\footnotetext{
* Mestrando em Educação pela Universidade Estadual de Maringá. E-mail: <kerosgustavo@gmail.com>

** Mestrando em Educação pela Universidade Estadual de Maringá. E-mail: <pauloribeiro1987@gmail.com>
} 
que o jogo de tabuleiro encontrado entre os índios Kadiweu é oriundo do grafismo, sendo chamado de "casa do rei" (VINHA, 2010, p. 29), e constitui-se de formatos circulares, não havendo, segundo a autora, distinção de poderes entre as peças, apenas distinções de cor.

A autora refere serem os jogos de tabuleiro atividades lúdicas que propiciam o desenvolvimento de estratégias de relacionamento social e fortalecem o construto das identidades étnicas. Como podem ser mediados pela prática educativa reflexiva, no entendimento da autora, contribuem para educar, proteger e ressignificar, revigorando identidades e formando pessoas qualificadas para compreender e usufruir conhecimentos vindos dos diferentes universos culturais brasileiros.

Na sequência, o texto de Artemis de Araújo Soares O Jogo de Bolinha de Gude (Peteca) praticado com Caroco do Tucumãa: estudo realizado com crianças indígenas da Amazônia baseado na teoria praxiológica de Pierre Parlebas apresenta resultados e análises de uma pesquisa realizada com crianças na Amazônia. A autora traz um breve histórico dos jogos de peteca no qual mostra que a primeira documentação sobre a utilização da peteca é encontrada na Grécia Antiga, existindo também registros desse jogo no Egito e no Oriente Médio. Atualmente é um jogo corriqueiro no quotidiano brasileiro e tem muitas variantes, podendo ser jogado em chãos diversos, como o asfáltico, o de barro e outros.

O texto demonstra que na literatura se encontram formas diferenciadas de regras do jogo em muitas partes do mundo e diferentes materiais utilizados na confecção das petecas, apresentando elementos como perseguição, viaduto, conquistador, Clube Glutton, trama, pote, dado, bolas de gude na cesta, recinto, entre outros.

Segundo informação da autora, a observação das crianças na comunidade indígena de Livramento, cujos habitantes, em sua maioria, pertencem à etnia Baré, evidenciou que as crianças se divertem de muitas formas, entre elas, com o jogo de bolinha de gude. As crianças mesmas confeccionam suas petecas, utilizando as sementes de tucumã, fruto de uma palmeira existente na região, e jogam de diferentes formas. Em sua análise praxeológica utilizando a teoria de Pierre Parlebas (SOARES, 2010, p. 37), a autora aponta que este brincar caracteriza-se, sobretudo, como uma atividade sociomotora de alternância, com lógicas homogêneas espaciais e temporais. Para a autora, é um jogo de contato e de comunicação e nele os participantes buscam a anulação de seus oponentes, mas é uma competição sem confrontos físicos em que se exercita uma atividade sociomotriz de alternância, realizada em ambiente estável, representando uma transmissão de ordem cultural de uma prática ludo-esportiva cuja lógica não se alterou ao longo da história. 
No terceiro texto temos a questão da formação de professores indígenas, com o trabalho intitulado $A$ educação física no projeto de autoria da Comissão PróÍndio do Acre. Escrito por Maria do Socorro Craveiro de Albuquerque, esse texto destaca a escassez de produção de materiais pedagógicos elaborados na língua indígena e evidencia a importância que a educação escolar indígena vem adquirindo no cenário acadêmico. Informa-nos a autora que, diante das demandas levantadas pelos professores indígenas do Acre, iniciou-se um trabalho de formação de professores que culminou com a instituição do Projeto de Autoria (uma experiência de autoria) iniciado em 1983. As ações consistiam na "[...] alfabetização de jovens das comunidades indígenas locais com finalidades de valor político e cultural relacionadas ao reordenamento positivo com a sociedade nacional e regional". Ainda segundo a autora, estas atividades relacionam-se "à valorização da língua e da cultura por meio da nova escola indígena [...]” (ALBUQUERQUE, 2010, p. 64). Pautando-se pelos princípios da interculturalidade e do bilinguismo, a autora defende que se elaborou uma nova educação escolar indígena. No campo da educação física, no âmbito interventivo, foram destacadas duas situações: de um lado, a constante solicitação dos professores por práticas corporais não indígenas, e de outro, a recomendação dos consultores para a discussão das práticas corporais no âmbito do Projeto de Autoria. A partir destes pressupostos foi discutido e elaborado um currículo para Educação Física com os professores indígenas.

Nesse processo, Albuquerque (2010) informa que foi selecionada uma gama de conteúdos e padrões corporais indígenas e não indígenas, bem como pesquisas sobre as brincadeiras de diferentes etnias, conhecimentos sobre brincadeiras de diversas culturas e estudos de caso sobre os esportes na sociedade não indígena e jogos indígenas. Para construir uma reflexão sobre práticas corporais, a autora retoma a ideia de Mauss (2003), no trabalho As técnicas corporais (1974), e também o entendimento de que o corpo é expressão da cultura e de que a cultura é captada através do corpo.

São elencadas algumas descrições da dinâmica indígena na compreensão do futebol. Alguns jogos e brinquedos indígenas também são contemplados em descrição minuciosa. A autora mostra que muitas brincadeiras populares, como a "cabra-cega", também são encontradas nas populações indígenas do Acre. Por meio das descrições dos jogos contextualiza as brincadeiras utilizando-se de discussão, formalização e interpretação das atividades lúdicas, bem como o sentido e a funcionalidade de tais práticas.

Buscando pautar-se pela teoria do ensino reflexivo, formação de competências e troca de experiências entre os pares, a autora analisa as competências de cada professor, a produção de materiais didáticos e reflexões fecundas no campo. A prática reflexiva, como conclui a autora em seu artigo, 
[...] foi o eixo estruturador do conhecimento e das aprendizagens dos professores indígenas, pois referenciou as diversas áreas do conhecimento, dando, consequentemente, sustentação política, metodológica e organizacional ao currículo e às escolas indígenas do Acre. (ALBUQUERQUE, 2010, p. 85).

Uma produção coletiva se apresenta no quarto texto, Jogos/Brincadeiras indígenas: A memória lúdica de adultos e idosos de dezoito grupos étnicos, de autoria de Beleni Saléte Grando, Severiá Idioriê Xavante e Neide da Silva Campos. O trabalho foi realizado junto aos alunos do $3^{\circ}$ ano de licenciatura indígena da Universidade do Estado de Mato Grosso - UNEMAT, com a elaboração de material didático da disciplina Educação Física. Para tanto, registrou-se a memória lúdica das crianças de dezoito etnias distintas. A autora elaborou um material pedagógico intercultural, para identificar quais brincadeiras estão presentes na cultura lúdica, na busca da sistematização de um material que valorize a importância da história desses povos pela potencialidade do Jogo, como forma de composição da relação ensino-aprendizagem.

As autoras retomam os preceitos de Berta Ribeiro (1988), segundo os quais o brinquedo é elemento da cultura e está diretamente relacionado com as atividades do quotidiano adulto. Nessa acepção, por meio do brincar as crianças aprendem as tarefas da vida adulta. Com estudo empírico buscou-se averiguar, entre os Baniwa, Rikbaktsa, Irantxe (Manoki), Ticuna, Terena, Tukano, Umutina, Paresi, Juruna, Bakairi, Trumai, Ikpeng, Bororo, Tapirapé, Xavante, Pataxó, Mehinako e Tapeba, "quais brincadeiras são específicas (tradicionais) nas diferentes etnias” (GRANDO; XAVANTE; CAMPOS, 2010, p. 92). Fundamentadas em Berta Ribeiro, as autoras afirmam que se podem dividir "os utensílios para o lazer infantil" dos povos indígenas em seis classes, assim apresentadas: "1) brinquedos trançados, com destaque ao 'pega-moças'; 2) brinquedos em dobraduras; brinquedos em cera; 4) brinquedos de barro; 5) camas de gato; 6) bonecos" (GRANDO; XAVANTE; CAMPOS, 2010, p. 93).

Após algumas considerações sobre as relações entre o brincar e a natureza, as autoras mostram que as brincadeiras ou jogos coletados podem ser utilizados nas aulas de Educação Física, desde que de forma discutida, pensada e recriada. Podem ainda ser utilizadas para o ensino das línguas indígena e portuguesa, e ainda para conhecer a história do povo e a relação com as novas práticas a partir do contato. Após apresentarem o registro das diferentes brincadeiras (jogos), nas considerações finais apontam que estas são, sobretudo, apropriações de significados, e que ao brincar reforça-se a identidade, o que permite aprender a ser alguém. As autoras destacam a necessidade de superar uma visão monocultural e fazem uma crítica ao que é genérico e universal afirmando que: 
Não há um índio genérico, como ninguém de nós é genérico, mas único, com uma sensibilidade e uma maneira de ser única, que, ao expressar-se expressa uma história que é individual e coletiva ao mesmo tempo. (GRANDO; XAVANTE; CAMPOS, 2010, p. 120).

Colocam como desafio esperado fazer com que "[...] os professores indígenas e os professores não indígenas, possam levar para a escola práticas sociais lúdicas, os JOGOS, como novas formas de perceber o Outro" (GRANDO; XAVANTE; CAMPOS, 2010, p. 121).

O quinto texto é também escrito por um coletivo de autores e se intitula Desafios: Atividades corporais e Etno-Matemática entre os Waimiri-Atroari, de Eduardo Sebastiani Ferrreira, Maria Beatriz Rocha Ferreira, Gláucio Campos Gomes de Matos, Marcelo Waimiri e Joanico Atroari. De início eles referem que a intersecção das áreas do conhecimento é um desafio, e propõem, para uma população indígena, um modelo "sob a ótica da Educação Física e da EtnoMatemática” (FERREIRA et al., 2010, p. 125). A pesquisa foi realizada com os indígenas Waimiri Atroari, local NAWA - Núcleo de Apoio Waimiri-Atroari. Os autores informam que a partir do contato iniciado na década de 1960, no contexto dos projetos desenvolvimentistas do governo militar, os WaimiriAtroari sofreram muita perda de população sendo que atualmente vivem 1.207 pessoas em dezenove aldeias do Sul do Estado de Roraima e do Norte do Amazonas, envolvendo estas comunidades: "[...] o curso de etnomatemática vem sendo desenvolvido nos últimos 12 anos" (FERREIRA et al., 2010, p. 126) de maneira interdisciplinar, contemplando Educação Física, Matemática e Física.

Pautando-se no psicodrama e na sociometria, os autores buscaram compreender a organização do espaço em salas de aula NAWA, em que se intercalam aulas teóricas e práticas. O lúdico e o jogo foram tratados como tema transversal, relacionando assuntos da Educação Física com a teoria e componentes da Física como força, velocidade, trajetória, aceleração, geometria; sendo estes alguns dos elementos trabalhados nas aulas de Educação Física.

Foram contemplados componentes da Educação Infantil e do Ensino Fundamental em conteúdos que intercalaram conceitos do cotidiano dos Waimiri e alguns conhecimentos científicos, segundo os autores, evitando-se juízos de valor. Os cursistas confeccionaram artesanatos e fizeram caçadas, elaborações numéricas, pescaria, construção de malocas, atividades livres e outras. Os autores avaliaram positivamente o trabalho coletivo, de ampla participação dos professores indígenas cursistas.

Abordando a contribuição das vivências corporais através do brincar na Educação Física Infantil, João Luiz da Costa Barros, no texto Vivências corporais através do brincar na Educação Física Infantil, foca o desenvolvimento da brincadeira 
e da criatividade, afirmando que nestas a criança enfrenta muitos desafios simbólicos e imaginários e busca a aprendizagem através de uma relação social compartilhada. Com a afirmação "As crianças brincam preparando-se para o futuro", feita pelo professor indígena Sateré-Mawé Ednelson Andrade Monteiro, o autor salienta que o brincar é de extrema importância para

[...] a criança garantir a permanência ao longo do tempo das experiências acumuladas pela comunidade indígena numa perspectiva de sobrevivência, identidade e evolução adaptativa ao mundo, sem perder de vista o tempo histórico de seu povo. (BARROS, 2010, p. 140).

Retomando o conceito de dialética, destaca a aquisição de conhecimentos por meio do brincar e defende a perspectiva de que se aprende a brincar com o convívio social, a partir do desejo de imitar os adultos. Apresenta alguns conceitos de Vygotsky (1998), como o desenvolvimento proximal e o desenvolvimento real e a atividade imitativa e criativa, para enfatizar a necessidade de educar os sentidos.

No trabalho desenvolvido, a construção de uma ação docente partiu do brincar na escola, considerando o incremento cultural da criança ao longo do seu desenvolvimento. $\mathrm{O}$ autor salienta a importância de evitar juízo de valores quanto aos conhecimentos e destaca as diferenças relativas às necessidades e especificidades de cada contexto. Defende uma escola segundo os ditames de Anísio Teixeira (1976), elaborada pela própria sociedade, com atividades integradas e organizadas, compreendendo assim uma "condição natural" de aprendizagem. Afirma que uma importante referência para a educação intercultural e interações do professor para uma realidade plural é a necessidade de compreender a teoria da zona de desenvolvimento proximal, pois este seria o nível em que os professores indígenas podem fazer avançar as capacidades atuais da criança indígena na escola. $\mathrm{O}$ texto traz algumas ideias sobre a ação docente enquanto prática social. Agrega o entendimento de Dewey (1936) sobre a importância das práticas corporais e comenta a finalidade da escola de possibilitar a socialização do saber, com base nas ideias de Saviani (1991). Finaliza apresentando algumas propostas de atividades para a vivência da prática corporal, concluindo ser o jogo um começo da ativação da imaginação da criança em todos os sentidos humanos. Ressaltamos a necessidade de a leitura e articulação dos estudos da Teoria Histórico Cultural, desenvolvida por Vygotsky e colaboradores russos, estarem articuladas ao seu fundamento teórico radical: a teoria marxista (DUARTE, 2006).

Por fim, o texto de Maria Aparecida Rezende, Frans Leeuwenberg e Luiz Augusto Passos, sistematiza o relato sobre uma Oficina de alfabetização para os Professores Xavante da Terra Indigena Pimentel Barbosa realizada "[...] junto com a produção da cartilha intitulada Dasa Uptabi: de volta às raízes" (REZENDE; LEEUWENBERG; PASSOS, 2010, p. 155), que resultou em um capítulo 
pedagógico na referida cartilha o qual relaciona o processo de alfabetização à história da coleta e do uso das vinte e duas espécies de batatas nativas conhecidas e usadas pelo povo Xavante.

O objetivo da oficina que deu origem ao texto foi "adaptar todos os jogos no contexto das diferentes batatas pesquisadas com as mulheres Xavante, grandes educadoras e coletoras de batatas silvestres" (REZENDE; LEEUWENBERG; PASSOS, 2010, p. 155). Destacamos a afirmação trazida pelos autores sobre o entendimento dos povos indígenas de que a escola é “[...] um dos instrumentos que os povos indígenas têm acreditado em seu potencial para auxiliar em suas lutas pelas terras, na revitalização de suas culturas [...]" (REZENDE; LEEUWENBERG; PASSOS, 2010, p. 155).

Entre as atividades contempladas e relatadas estão a construção do alfabeto móvel usado na língua xavante e roteiros para que o professor trabalhe a forma de escrever o nome das batatas. Isto possibilita a alfabetização e a construção do "jogo da memória”, que, segundo os autores, “[...] ajuda memorizar: o desenho e o nome de cada parte das batatas" (REZENDE; LEEUWENBERG; PASSOS, 2010, p. 162). Outras atividades foram desenvolvidas: o bingo de letras e o bingo de palavras, que começam com os estudantes construindo as peças do jogo e as cartelas; o jogo de baralho, preparado pelo professor com regras que são definidas, mas devem ser apresentadas e mudadas durante o processo de ensino. Contemplaram-se também atividades de literatura, em que os estudantes foram levados à casa de uma historiadora para ouvir histórias sobre as batatas, passeios de campo pelo cerrado e pela mata, onde procuraram e colheram batatas, e, ao longo do passeio o professor trabalhou noções de espaço, medidas, entre outras. Como estratégia metodológica, o texto orienta que ao final de cada atividade se façam um relatório e uma correção coletiva.

Os textos convergem em relação ao tema proposto e apresentam elementos reflexivos, analíticos, com canais de diálogo e compartilhamento, buscando na cultura indígena a memória e a vivência como forma de sistematizar um conhecimento a ser ensinado na escola indígena. Baseiam-se no princípio da interculturalidade e defendem uma escola que trabalhe os conteúdos da cultura indígena pela cultura indígena, trazendo para a escola elementos do cotidiano.

Ressaltamos a afirmação de que a escola indígena é um instrumento de luta por terras, condições de vida digna e manutenção das culturas indígenas. Entendemos que nessa luta é possível articular os conhecimentos tradicionais indígenas com o conhecimento sistematizado, elaborado pela humanidade e transmitido pela escola. Reforçamos a importância dos processos de ensino e aprendizagem, da formação dos professores e da presença de estratégias materiais diversificados de ensino e aprendizagem. As orientações da Teoria Histórico-Cultural de Vygotsky (1998) e colaboradores, mencionadas no livro, indicam ser 
a escola um local privilegiado para oportunizar o máximo de desenvolvimento das potencialidades humanas de todas as crianças, independentemente de sua condição cultural, para que, sendo instrumentalizadas em seu intelecto e movimentando seu pensamento possam agir refletidamente na luta pela cultura de seu povo e pela garantia de suas terras.

\section{Referências}

ALBUQUERQUE, M. do S. C. de. A educação física no projeto de autoria da comissão próíndio do Acre. In: GRANDO, B. S. (Org.). Jogos e culturas indígenas: possibilidades para a educação intercultural na escola. Cuiabá: EdUFMT, 2010. p. 61-87.

BARROS, J. L. da C. Vivências corporais através do brincar na Educação Física Infantil. In: GRANDO, B. S. (Org.). Jogos e culturas indígenas: possibilidades para a educação intercultural na escola. Cuiabá: EdUFMT, 2010. p. 137-151.

DEWEY, J. Democracia e educação. São Paulo, Companhia Editora Nacional, 1936.

DUARTE, N. Vigotski e o "aprender a aprender": crítica às apropriações neoliberais e pós-modernas da teoria vigotskiana. 4. ed. Campinas: Autores Associados, 2006.

FERREIRA, E. S.; FERREIRA, M. B. R. F.; MATOS, G. C. G. de; WAIMIRI, M.; ATROARI, J. Desafios: atividades corporais e etno-matemática entre os Waimiri-Atroari. In: GRANDO, B. S. (Org.). Jogos e culturas indígenas: possibilidades para a educação intercultural na escola. Cuiabá: EdUFMT, 2010. p. 123-135.

GALLAHUE, D. L.; OZMUN, J. Compreendendo o desenvolvimento motor: bebês, crianças, adolescentes e adultos. Rio de Janeiro: Editora Phorte, 2005.

GRANDO, B. S.; XAVANTE, S. I.; CAMPOS, N. da S. Jogos/brincadeiras indígenas: a memória lúdica de adultos e idosos de dezoito grupos étnicos. In: GRANDO, B. S.(Org.). Jogos e culturas indígenas: possibilidades para a educação intercultural na escola. Cuiabá: EdUFMT, 2010. p. 89-122.

MAUSS, M. Sociologia e Antropologia. São Paulo: Cosac \& Naify, 2003.

REZENDE, M. A.; LEEUWENBERG, F.; PASSOS, L. A. Oficina de alfabetização para professores. In: GRANDO, B. S. (Org.). Jogos e culturas indígenas: possibilidades para a educação intercultural na escola. Cuiabá: EdUFMT, 2010. p. 153-166.

RIBEIRO, B. 90 objetos rituais, mágicos e lúdicos. In: RIBEIRO, B. Dicionário do artesanato indígena. Belo Horizonte: Itatiaia; São Paulo: Ed. USP, 1988. p. 285-318.

SAVIANI, D. Pedagogia histórico-crítica: primeiras aproximações. São Paulo: Cortez, 1991.

SOARES, A. de A. O jogo de bolinha de gude (peteca) praticado com caroço de tucumã: estudo realidade com crianças indígenas da Amazônia baseado na teoria da praxiológica de Pierre Parlebas. In: GRANDO, B. S. (Org.). Jogos e culturas indígenas: possibilidades para a educação intercultural na escola. Cuiabá: EdUFMT, 2010. p. 35-60.

TEIXEIRA, A. Educação no Brasil. 2. ed. São Paulo: Ed. Nacional, 1976. 
VINHA, M. Jogo de tabuleiro como prática educativa intercultural. In: GRANDO, B. S. (Org.). Jogos e culturas indígenas: possibilidades para a educação intercultural na escola. Cuiabá: EdUFMT, 2010. p. 21-33.

VYGOTSKY, L. S. A formação social da mente: o desenvolvimento dos processos superiores. São Paulo: Martins Fontes, 1998. 